\title{
Political Context, Organizational Mission, and the Quality of Social Services: Insights from the Health Sector in Lebanon
}

\section{Citation}

Cammett, Melani, and Aytuğ Șașmaz. 2017. Political Context, Organizational Mission, and the Quality of Social Services: Insights from the Health Sector in Lebanon. World Development 98: 120-32.

\section{Permanent link}

http://nrs.harvard.edu/urn-3:HUL.InstRepos:41542959

\section{Terms of Use}

This article was downloaded from Harvard University's DASH repository, WARNING: This file should NOT have been available for downloading from Harvard University's DASH repository.

\section{Share Your Story}

The Harvard community has made this article openly available.

Please share how this access benefits you. Submit a story.

\section{Accessibility}




\title{
Political Context, Organizational Mission, and the Quality of Social Services: Insights from the Health Sector in Lebanon
}

\author{
MELANI CAMMETT and AYTUĞ ŞAŞMAZ* \\ Harvard University, Cambridge, USA
}

\begin{abstract}
Summary. - Non-state actors are important providers of social welfare. In parts of the Middle East, South Asia, sub-Saharan Africa, and other regions, religious charities and parties and NGOs have taken on this role, with some preceding independent statehood and others building parallel or alternative welfare infrastructure alongside the modern state. How well do these groups provide welfare goods? Do some exhibit a "welfare advantage," or a demonstrated superiority in the quality and efficiency of providing social services? In this paper, we explore whether distinct organizational types are associated with different levels of the quality of care. Based on a study in Greater Beirut, Lebanon, where diverse types of providers operate health centers, we propose and test some hypotheses about why certain organizations might deliver better services. The data indicate that secular NGOs, rather than religious, political or public sector providers, the other main types of providers in the charitable sector, exhibit superior measures of health care quality, particularly with respect to objective provider competence and subjective measures of patient satisfaction. In Lebanon, where religious and sectarian actors dominate politics and the welfare regime and command the most extensive resources, this appears to be a counterintuitive finding. Our preliminary explanation for this outcome emphasizes the ways in which the socio-political context shapes the choices of more qualified or professional doctors to select into secular providers, in part because of their organizational missions, and why citizens might perceive these providers to be better, irrespective of the actual quality of services delivered.

(c) 2017 Elsevier Ltd. All rights reserved.
\end{abstract}

Key words - social services, religion, NGOs, health, health quality measurement, Middle East

\section{INTRODUCTION}

In many developing countries, non-state actors are important providers of social welfare, with some preceding independent statehood and others building parallel or alternative welfare infrastructure alongside the modern state. A wide array of actors, including NGOs, religious charities, and even political parties, are in the business of providing health services, schooling, vocational training, and other important services, and thus greatly affect the standards of living and well-being of low- and middle-income people (Cammett \& MacLean, 2014). Yet little research explores the quality of welfare goods supplied by NSPs. Do certain types exhibit a "welfare advantage," or a demonstrated superiority in the quality of social service provision?

In this article, we propose and assess a variety of hypotheses related to organizational type and the quality of services and develop some propositions about the effects of organizational mission on service delivery. Based on evidence from an original set of surveys in primary health centers affiliated with diverse public and non-state actors in Greater Beirut, Lebanon, we show that secular NGOs demonstrate an apparent welfare advantage over other provider types in both objective and subjective measures of health quality. ${ }^{1}$ Further, patient evaluations of health centers run by distinct organizations are driven largely by perceptions of doctors, and doctors who work in secular organizations report higher levels of satisfaction with the organizations where they work. This apparent secular welfare advantage contradicts many theoretical and empirical expectations, as we detail below. Our proposed explanation for this result centers on the ways in which the political context affects both the objective and subjective quality of care by secular, religious, and political groups through supply and demand processes. In a polity structured explicitly along religious lines, being an avowed secularist goes against dominant social and political trends and offers few if any material rewards because such groups do not have access to the resources needed to run patronage networks, which are associated with more politically connected religious and sectarian organizations. As a result, secular NGOs that provide health services may attract doctors who are more inspired by intrinsic motivations, such as charitable considerations or a commitment to professionalism. Second, widespread citizen dissatisfaction with religious and sectarian organizations, ${ }^{2}$ which are often viewed as corrupt and self-serving in polities where they are involved in national politics, may result in inferior evaluations of welfare programs run by these types of groups and, conversely, more favorable assessments of services provided by organizations that explicitly dissociate themselves from political sectarianism.

In the next section, we justify our focus on the health sector, present a multidimensional definition of "quality" in primary health care, and review arguments about why some types of

\footnotetext{
* We are indebted to Walid Ammar, Matthew Blackwell, Jennifer Brass, Jishnu Das, Randa Hamadeh, Michael McGinnis, Mona Osman, Soledad Prillaman, Tariq Thachil, Dustin Tingley, Teppei Yamamoto and Nasser Yassin for valuable feedback and input on this research. In addition, the research benefited from the comments of participants at the Yale Leitner and Comparative Politics Workshops, Princeton Comparative Politics Workshop, AALIMS 2015 Conference, Oxford Political Science Seminar, London School of Economics Political Science Seminar, Gothenburg University Political Science Seminar, MIT Conference on Political Behavior in Developing Contexts, and the Ostrom Workshop at Indiana University. We also gratefully acknowledge Nasser Yassin and the Faculty of Health Sciences at the American University of Beirut for facilitating the administrative components of the project in Lebanon. Sawsan Allam and Saria El-Khazen served as excellent project managers. Generous funding to support this research came from Brown University's Global Health Initiative Grant. Final revision accepted: April 10, 2017.

$U R L:$ http://www.melanicammett.net.
} 
providers may be especially adept at providing health care and other types of social services. The third section of the paper provides essential background information on Lebanon and on the types of organizations in question and describes the data and key variables used in the analyses. Section four presents descriptive and statistical analyses followed by a discussion of the implications of the findings for the relationships between organizational mission, political context, and the quality of service delivery. In the conclusion, we summarize the findings and suggest a broader research agenda on political context, organizational mission, and the quality of service delivery.

\section{POLITICS, HEALTH, AND DIMENSIONS OF HEALTH CARE QUALITY}

For a variety of reasons, social scientists - and not just public health and medical specialists - should be concerned with the politics of health, and the health sector is an appropriate arena for examining whether different types of organizations exhibit a welfare advantage. First, because many NSPs are involved in the delivery of medical services (Cammett, 2014; Thachil, 2014) and access to health care is important to well-being, people may feel indebted to institutions that provide or mediate access to medical services. Second, cognizant of these potential payoffs, political organizations face incentives to deliver or claim credit for the provision of health care. Third, the health system is a critical locus of citizen interactions with governments, which play an important role in the financing and provision of health care in middle-income countries (Rockers, Kruk, \& Laugesen, 2012) and with non-state providers, which are either well established or increasingly important in welfare regimes in developing countries (Cammett \& MacLean, 2014; Wood \& Gough, 2006). Finally, in societies with politicized ethno-religious identities, as in Lebanon, the provision of basic services also helps to constitute a sense of group membership by establishing boundaries of inclusion and exclusion in political communities (Cammett, 2014). Thus, the provision of health care intersects with politics in both direct and indirect ways.

\section{(a) Measuring health care quality}

In the literature on health policy and management, it is widely accepted that quality encompasses multiple dimensions, including objective and subjective measures as well as technical and non-technical factors. In broad terms, health care quality includes three components related to the structure, process, and outcome of the delivery of health services, respectively (Donabedian, 1988; Klassen et al., 2010). The structural dimension of quality refers to the environment in which health care is provided, or the material and human resources and characteristics of the facility where services are delivered as well as the organization of the delivery of medical services. This includes the availability and condition of medical equipment and trained medical staff, medications, and relevant infrastructure as well as the ways in which physical and human resources are managed up and down the supply chain in the delivery of care. The process-oriented component of quality addresses the method by which health care is provided, focusing in particular on the ways in which providers interact with patients as well as provider capabilities and effort. Process measures assess doctor knowledge and training as well as the degree to which they apply this knowledge to deliver appropriate care to patients in a timely and respectful manner.
Finally, outcomes denote the results of health care, notably the health status of patients and patient satisfaction, among other factors (Stelfox \& Straus, 2013; Tuan, Dung, Neu, \& Dibley, 2005).

Two points related to the conceptualization and measurement of health care quality should be emphasized and guide our choice of indicators. First, health outcomes result from a variety of factors above and beyond the delivery of services (Wilkinson \& Marmot, 2003), complicating efforts to link them definitively to the provision of medical care. As a result, our analyses do not aim to explain health outcomes. Second, public health research shows that the process dimensions outweigh the structural aspects of quality in affecting health outcomes (Das \& Hammer, 2014). A doctor who is well-trained, regularly shows up to work, and practices medicine at their "knowledge frontier" has a greater impact on patient health than the mere availability of medical supplies and new machines. Without capable and committed professional staff, state-of-the-art medical equipment has little effect on patient health. Likewise, patients are more likely to report more favorable views of their service providers when they seem competent, engaged, and attentive, even when the facility in which the care is provided is less attractive and less well appointed. Thus, while we account for the structural dimensions of quality in our analyses, we focus most centrally on process quality. Furthermore, most of statistical analyses aim to explain subjective measures of quality, notably patient satisfaction, because perceptions of performance rather than objective measures of quality are more germane to citizen evaluations of providers and, therefore, are likely to have a more direct impact on political attitudes and preferences (Cammett, Lynch, \& Bilev, 2015; Christensen \& Lægreid, 2005). Indeed, our hypotheses, which highlight the reasons why competent doctors select into some provider organization and why some patients report more favorable views of some provider types, are more directly relevant to the process-oriented dimensions of medical care.

\section{ORGANIZATIONAL MISSION AND THE QUALITY OF SERVICE DELIVERY}

Distinct social science approaches, which we review briefly below, either directly or indirectly suggest that different types of organizations are likely to exhibit a welfare advantage (or disadvantage).

\section{(a) Faith-Based organizations and charitable motivations}

A substantial literature on faith-based organizations (FBOs) holds that the charitable dimensions of religion motivate the pious to volunteer or work for minimal compensation to do social good (Clarke, Jennings, \& Shaw, 2007; Cnaan \& Boddie, 2002; DeHaven, Hunter, Wilder, Walton, \& Berry, 2004; Unruh \& Sider, 2005; Wuthnow, 2004). These approaches hold that religious organizations tend to attract personnel who are committed to their missions on spiritual grounds, making them willing to put in long hours, often for relatively minimal compensation. In addition, staff members and volunteers in religious charities may choose to serve others to ensure the survival of the congregation through income-generating activities or to foster acceptance of the religious group in the community where it is based. Social service provision may also aid in proselytism, a potentially powerful incentive for the leadership and staff of religious organizations to offer high-quality services and one that is relatively unique 
to religious groups. A recent special issue of the Lancet on religion and health care echoes some of these claims (Karam, Clague, Marshall, \& Olivier, 2015; Summerskill \& Horton, 2015). ${ }^{3}$

\section{(b) The economics of religion and "Strict" churches}

The literature on the economics of religion points to a related yet distinct reason why certain subtypes of FBOs may deliver superior welfare services. "Strict churches" (Iannaccone, 1994), or religious groups that require major sacrifices from their members and call on adherents to visibly distinguish and distance themselves from the rest of society, exhibit higher rates of volunteerism and attract more devoted personnel than others. ${ }^{4}$ The high levels of commitment of their members enables such groups to weed out less committed individuals, thereby overcoming the free rider problems that plague most organizations, including less stringent FBOs. The selection effects at the core of this approach in turn may affect the quality of services by incentivizing staff to devote more effort to their work for little or no compensation.

Organizational strictness may be associated with higher levels of subjective and objective quality. On the one hand, organizations that expect big sacrifices on the part of their members may attract especially committed professionals, who are likely to work to their "knowledge frontier" (Das, Hammer, \& Leonard, 2008), leading to higher levels of objectively measured quality of service delivery. On the other hand, beneficiaries and community members may perceive that staff members at facilities run by strict groups are more likely to be self-sacrificing, to work especially hard, and to remain committed to their cause, leading to higher subjective measures of service quality.

\section{(c) Ethnoreligious parties and political incentives}

When adapted to the political arena, similar logics may apply to ethnic or sectarian parties, which combine communal and political messages. At the individual level, identity-based parties with affiliated social service wings, such as Hezbollah in Lebanon, Hamas in Palestine, the Bharatiya Janata Party in India, and other ethnic and religious parties, may attract volunteers and staff members who are willing to put in long hours at party-linked institutions, whether because of genuine commitment to the cause, integration in party patronage networks or both. At the organizational level, the drive to win votes or to galvanize non-electoral mobilization constitutes a strong incentive for political groups to offer high-quality services (Cammett, 2014; Thachil, 2014). Ethnic and sectarian parties may therefore face high incentives to offer attractive and well-run social programs.

However, if sectarian parties operate according to a clientelist logic rather than an ideological vision, then staff members at party-linked institutions may be less inclined to make personal sacrifices on behalf of party. In comparison with more intrinsic motivations, such extrinsic incentives potentially reduce the drive to provide high-quality services. Similarly, community members may view the welfare agencies linked to corrupt, patronage-based parties with cynicism, reducing subjective evaluations of the quality of services offered by such institutions.

These distinct approaches suggest that FBOs may deliver better social services than other types of providers, whether because their religious missions incentivize staff members to provide high-quality charitable services or because they attract especially committed personnel and, therefore, more effectively overcome free rider problems plaguing other organizations. Some evidence also suggests that sectarian parties-particularly those that emphasize a strong ideological mission-may provide relatively high-quality services under some conditions. Furthermore, the sacrifices that staff members make by working at charitable organizations rather than for-profit institutions may also garner higher subjective measures of quality.

\section{(d) A public sector welfare disadvantage?}

Much development research focuses on the role of the public sector in service delivery, particularly in the face of government fiscal crises in developing countries (World Bank, 2004; inter alia). ${ }^{5}$ Indeed, some studies of the provision of services by FBOs parties benchmark service delivery by these organizations against that of state agencies (DeHaven et al., 2004; Karam et al., 2015; Reinikka \& Svensson, 2010; Summerskill \& Horton, 2015). Other work compares the extent and quality of services provided by government institutions with those of the for-profit private sector, which is the fastest growing provider of basic services in many developing countries (Basu, Andrews, Kishore, Panjabi, \& Stuckler, 2012; Berendes, Heywood, Oliver, \& Garner, 2011; Das \& Hammer, 2007). While a large body of work examines the conditions under which state agencies provide better services, an overarching theme is that the public sector faces constraints in effective service delivery (World Bank, 2016). Ultimately, the extent to which this is true is an empirical question that is likely to be contingent on specific socio-political and economic conditions and to vary by type of service and dimension of quality, as our results suggest.

In the next section, we describe the sample and data used to assess whether certain provider types in Lebanon exhibit a welfare advantage, whether measured in objective or subjective terms.

\section{SAMPLE DESIGN AND DATA COLLECTION}

Lebanon is an appropriate site for this research because a broad range of primary health care providers and non-state actors operate in the welfare regime and most are well established. The Lebanese government is based on a powersharing arrangement, which enshrines religion in the political system and stipulates that government posts are allocated by sect according to a pre-established formula, effectively leading to the distribution of public resources along sectarian lines (Salti \& Chaaban, 2010).

The sectarian power-sharing system in Lebanon has shaped the post-independence welfare regime, which involves minimal state intervention and relies heavily on private, non-state actors, including religious charities, sectarian parties, and NGOs. As a result, the Lebanese case is most directly comparable to contexts with politicized ethnic or religious cleavages, a phenomenon that is increasingly common in the Middle East and South Asia, among other places. However, the Lebanese experience offers pertinent lessons for Middle Eastern and other developing countries in the contemporary period, when public welfare infrastructure is declining, non-state provision is on the rise and systems based on hybrid governance models are promoted by development policies (Brass, 2016; Brinkerhoff, 1999; Evers, 2005; Pestoff \& Brandsen, 2013).

In the health sector, the state plays a minimal role in the actual delivery of health services but provides extensive financing for non-state providers. The major sectarian parties and movements hold great sway in public institutions through 
the sectarian power-sharing system, perpetuating weak state capacity and effectively inhibiting reform. As a result, state efforts to build a more robust public welfare infrastructure and to exert more regulatory control over private and nonstate actors in the welfare regime have met stiff resistance, although the Ministry of Public Health has increased its stewardship of the health sector in recent years. In this system, state agencies and social programs are lucrative sources of patronage for parties, political movements, and local politicians, creating entrenched interests in the status quo (Cammett, 2014).

Although the majority of health care providers in Lebanon work in the for-profit private sector, the charitable sector, which caters to poor and lower middle class people, is a vital and growing component of the health system and is an important partner in the Lebanese Ministry of Public Health's (MOPH) plan to offer universal coverage to the population. The MOPH network of health centers, which is the focus of this paper, features both public sector and non-state providers. In exchange for providing heavily subsidized medical services, the MOPH provides non-financial resources and access to free or heavily subsidized medications to centers that meet minimum standards. Many of the centers in MOPH network also serve Syrian refugees, who had come to constitute nearly one-quarter of the population of Lebanon by the time of data collection in mid-2014.

We classify the health centers operating in the MOPH network into four main types, including facilities run by the public sector, secular NGOs, religious charities, and political parties. In Lebanon, coding these centers is a relatively straightforward process as most belong to networks with clear organizational affiliations. Facilities coded as public include those run by a government agency, whether national or municipal. Secular NGOs refer to non-state providers that have no religious or political affiliation and often broadcast their mission in explicitly non-sectarian terms. Religious centers are those linked to a religious community, such as the Maronite Church, a Sunni religious institution, or other religious affiliation, but are not linked to a political party or movement. Finally, political facilities are directly run by a political party or movement that contests elections or holds public office or a party-linked charitable arm. In Lebanon, where virtually all of the major political parties are sectarian-that is, political groups with religious affiliations-party-linked centers are associated with particular religious communities but, again, are distinct from religious charities. Examples include the health networks of the predominantly Sunni Future Movement, Shi'a Hezbollah and Amal Movement, and Christian Kataeb Party. Religious charities and sectarian political parties run about two-thirds of primary health facilities in the network. Of the remaining one-third of charitable centers, about $60 \%$ are run by secular groups (Cammett, 2014). ${ }^{6}$

In virtually all charitable health centers, doctors work on a part-time basis, earning a standard, minimal fee calculated on a per patient basis, while devoting most of their time to their own or other private, for-profit practices. As a result, the rate and structure of compensation for doctors working in facilities run by different types of providers is unlikely to explain variation in health care quality. In addition, all providers receive funding from international organizations and donors, and therefore differences in quality is not likely to result from the input of such types of foreign actors.

\section{(a) Sample}

The sample design for the pilot study followed the following procedures. First, all centers in the sample are part of the
MOPH charitable network. Second, all facilities in the sample operate on a not-for-profit basis and primarily serve poor and low-income families. Third, the sampled facilities are drawn from the universe of centers located in Greater Beirut, which contains the highest population concentration in the country and features health centers run by all provider types. It is also important to note that most centers in the MOPH network are run by a parent organization such as a religious charity, political party or NGO, which has multiple facilities across the country. Given that all sampled centers were in the MOPH network and are located in the capital, we expect the sample to be somewhat biased toward higher quality services.

The data collection team was able to collect relatively complete data on 27 of the 36 centers located in Greater Beirut in the MOPH primary health care network. Table 1 summarizes the distribution of PHCs in the sample across different types of provider organizations, the key variable of interest in this paper, and sample sizes for each data collection instrument.

\section{(b) Data collection procedures}

The data collection for this study entailed the design and implementation of multiple original surveys. ${ }^{7}$ Cammett trained a team of enumerators who then carried out the following surveys in the selected health care facilities: (1) survey interviews with the chief medical officer and medical staff to obtain information on the services and infrastructure available at the facility and on management and training procedures, among other issues; (2) direct observation of clinical examinations; (3) exit interviews with patients at the selected facilities; and (4) medical vignettes administered to general practitioners at each facility to assess their medical knowledge and advice. Several months after data collection was complete, Cammett then conducted in-depth interviews with the directors of the health networks represented in the sample.

The chief medical officer survey provides crucial baseline information on each health center. The questionnaire gathers data on the number, educational background, experience, and compensation structure of each employee as well as the operating budget of the facility; ${ }^{8}$ the average patient load during the past year and epidemiological profiles of the patients; available infrastructure at the facility related to the work environment and to medical procedures and examinations; and internal procedures for monitoring the performance of doctors and nurses at the facility and, more generally, for human resource management. The chief medical officer survey therefore provides data on infrastructural quality and on some dimensions of process quality at the facility level.

A second method of data collection provides information on the nature of interactions between doctors and patients based on direct observation by the trained enumerators of clinical examinations. The data collected include information about the patient, such as her symptoms, age, gender; information about the doctor's interactions with the patient, notably the number of questions asked by the doctor and the types of examinations and treatments given; and the prices charged for the services rendered. These data provide relatively objective information on the nature of doctor attentiveness to the patient. Although the findings are subject to Hawthorne effects, ${ }^{9}$ this source of bias may decline with the time spent observing (Leonard \& Masatu, 2006). Furthermore, the bias due to Hawthorne effects should be consistent across all centers, enabling comparative analyses of the data collected.

Third, patient exit surveys were carried out at the health centers to assess patient perceptions of the care they have received. The survey collects basic information on patient 
Table 1. Institutional types of primary health centers in the sample

\begin{tabular}{lccccc}
\hline Type of facility & $\begin{array}{c}\text { Number of facilities } \\
\text { in the study }\end{array}$ & $\begin{array}{c}\text { Sample size of chief } \\
\text { medical officer survey }\end{array}$ & $\begin{array}{c}\text { Sample size of } \\
\text { direct observations }\end{array}$ & $\begin{array}{c}\text { Sample size of } \\
\text { patient exit interviews }\end{array}$ & $\begin{array}{c}\text { Sample size of } \\
\text { medical vignettes/doctor } \\
\text { surveys }\end{array}$ \\
\hline Public institutions & 4 & 4 & 15 & 16 & 5 \\
Secular NGOs & 5 & 5 & 15 & 63 & 5 \\
Religious charities & 11 & 11 & 42 & 42 & 13 \\
Political charities & 7 & 7 & 135 & 137 & 43 \\
Total & 27 & 27 & & 42 & 5 \\
\hline
\end{tabular}

characteristics such as education, wealth and age; self-reported health status; aspects of the doctor-patient interaction; and patient satisfaction. These responses provide a subjective measure of the quality of care by diverse types of providers.

A final survey entailed the administration of medical vignettes to doctors at the health centers to assess their medical knowledge. Two trained researchers conducted the interview with the doctor, with one serving as a "patient" and the other as the "recorder." They presented four cases of health conditions or illnesses, which were adapted to the Lebanese epidemiological profile, experienced by distinct hypothetical patients who vary by age and gender. ${ }^{10}$ Each vignette began with the patient presenting her symptoms and the recorder inviting the doctor to proceed exactly as she would for a normal patient. In response to every history question, the patient provided a standardized response that was carefully rehearsed in advance. Similarly, any physical examination requested by the doctor was followed by a standardized answer offered by the recorder. After the doctor gave the diagnosis and treatment plan, the pair of enumerators administered the next hypothetical case. The information gathered from clinician responses is used to construct an index of medical knowledge and advice of the medical staff from different types of providers, generating a relatively objective measure of process quality and, more specifically, of doctor competence.

Finally, Cammett carried out in-depth interviews with MOPH officials and the directors of the health centers and networks included in the sample. These interviews gathered information on the history of the health programs run by different institutions; the organizational missions of the parent networks; staff selection, training and management procedures; the finances and budgets of the health networks and individual facilities; and other relevant information. The data from these interviews fill in some gaps in the survey data, particularly related to finances and doctor compensation schemes and to the role of organizational mission in shaping the health programs of diverse non-state institutional networks.

\section{DESCRIPTIVE ANALYSES: INDICATORS OF HEALTH CARE QUALITY AND VARIATION ACROSS PROVIDER TYPES}

As explained above, health care quality includes three components related to the structure, process and outcome of the delivery of health services. Table 2 provides summary statistics for the selected measures of quality, and means and standard deviations for each provider type.

The first measure, "workplace equipment", which relates to infrastructural quality, captures the availability of materials and equipment essential to run a clean and functional working environment for the delivery of primary health services. This variable is a composite index based on a checklist of items available in the clinic. The second variable, "health equipment," is also a composite index measuring the availability of material and equipment used in medical diagnoses and treatment. ${ }^{11}$

The means in Table 2 indicate that the availability of infrastructure, whether related to the administrative functioning of the centers or to medical equipment, is roughly similar across all types of non-profit providers. The average scores for the availability of medical equipment are somewhat lower but also relatively high, and the values do not vary widely across the different types of health networks. T-tests comparing the mean levels of these variables indicate that measures of infrastructural quality do not differ significantly across all provider types. This is not surprising that membership in the MOPH primary care network requires that facilities meet baseline standards for the availability and maintenance of equipment and supplies.

Two composite indicators measure governance at the level of the facility based on questions in the chief medical officer survey. The first, "organizational monitoring," is an index to gauge oversight policies and practices within the network and facility itself. The variable is an additive index to assess whether the administration employs one or more methods of monitoring the health center, including visits by representatives from the parent organization, the implementation of personnel surveys to obtain feedback on staff concerns, and the fielding of patient satisfaction surveys. A second indicator, "good governance," is a more comprehensive index of facility-level supervision and management and includes variables related to external monitoring by the MOPH and internal oversight by the administration of the facility. The index is based on an average of six indicators, each of which ranges from 0 to 1 , including regular visits by government health inspectors to the facility, regular visits by the parent organization to inspect the facility, the administration of patient satisfaction surveys, the collection of staff surveys, regular staff meetings, and institutionalized channels of communication between staff members and the management of the center.

As seen in Table 2, across the four types of providers, no major differences are evident in the extent to which organizations monitor their facilities or promote feedback and dialog with staff and patients. T-tests comparing the mean levels of these variables confirm that levels of internal monitoring and governance do not differ significantly across all provider types. Again, this lack of variation may reflect the need to comply with a set of basic management practices to meet the conditions for membership in the MOPH primary health care network. Given the real and perceived deficiency of public service provision in academic research (World Bank, 2004, 2016) and in the Lebanese context, ${ }^{12}$ the lack of variation in certain dimensions of health care quality across provider types - including the public sector-is an important and counterintuitive finding worthy of further research.

Another measure of process-related quality, doctor effort, is derived from direct observations of clinical examinations. One 




measure of doctor effort records the number of physical examinations of the patient by the doctor (Das et al., 2008). ${ }^{13}$ As seen in Table 2, this variable also does not suggest meaningful variation across provider types, a finding confirmed by the results of a t-test. In fact, the means and standard deviations for each provider type are quite close to each other. This finding is more surprising vis-à-vis some theories presented above, which imply that staff members at religious facilities - and especially at facilities run by religious orders that make great demands on their adherents-would exert more effort to their work in institutions run by the religious order.

The medical vignettes provide a wealth of information related to process quality, focusing on doctors' medical knowledge. Based on four vignettes of different health conditions commonly found in Lebanon, we construct an indicator of "doctor objective knowledge," which gauges the number of vignettes diagnosed correctly by the doctor and ranges from 0 to 4 . This measure points to a potential welfare advantage by secular NGOs. As seen in Table 2, doctors in NGOs earn the highest average score with 2.3 conditions correctly diagnosed, whereas the average scores for other organizational types are all approximately one correct diagnosis out of four. A t-test comparing the average number of correct diagnoses of doctors in the NGO type with the mean of all other provider types also suggests that the difference is statistically significant at the $10 \%$ level $(t=-2.3527$, $\mathrm{df}=4.224, p$-value $=0.07483$ ). This finding provides suggestive evidence that NGOs somehow recruit more competent doctors.

Finally, the indicators we use for outcome-related quality are subjective measures of satisfaction reported by patients for the reasons we note earlier in the paper. In two different questions, patients report their levels of satisfaction with the health center and with their doctor, respectively. Patient satisfaction also exhibits meaningful variation across provider types, again with secular NGOs displaying the highest overall values on related measures. The average score of patient satisfaction with the center is almost 4.3 for secular NGOs, whereas it is around 3.7 for other types. Similarly, the average score of patient satisfaction with the doctor is 4.4 for secular NGOs, whereas it is around 3.7 for other organizational types. A t-test comparing the mean values of patient satisfaction with the doctor in secular NGOs and in other types of providers also indicates that the difference is statistically significant at the $1 \%$ level $(t=-3.4446$, $\mathrm{df}=16.769, p$-value $=0.003146)$. This result indicates that patients have more favorable perceptions of doctors at NGOs than at other types of facilities, regardless of whether or not the quality of care was superior by more objective measures.

In sum, descriptive analyses indicate that measures of quality in primary health care are similar across provider types for structural indicators, such as the availability of administrative and medical infrastructure, and some dimensions of process-related indicators, notably governance procedures and provider effort at the facility level. Measures of doctor knowledge and patient satisfaction, however, vary across provider types, with secular NGOs exhibiting a distinct advantage in both areas. In the next section, we explore these descriptive findings in more detail to see if the apparent secular welfare advantage still holds after controlling for potential confounders, and if so, which characteristics of NGO-run health centers and of doctors at these facilities might contribute to explaining this variation. 
Table 3. Regression results regarding provider type and patient satisfaction with the health center and with the doctor

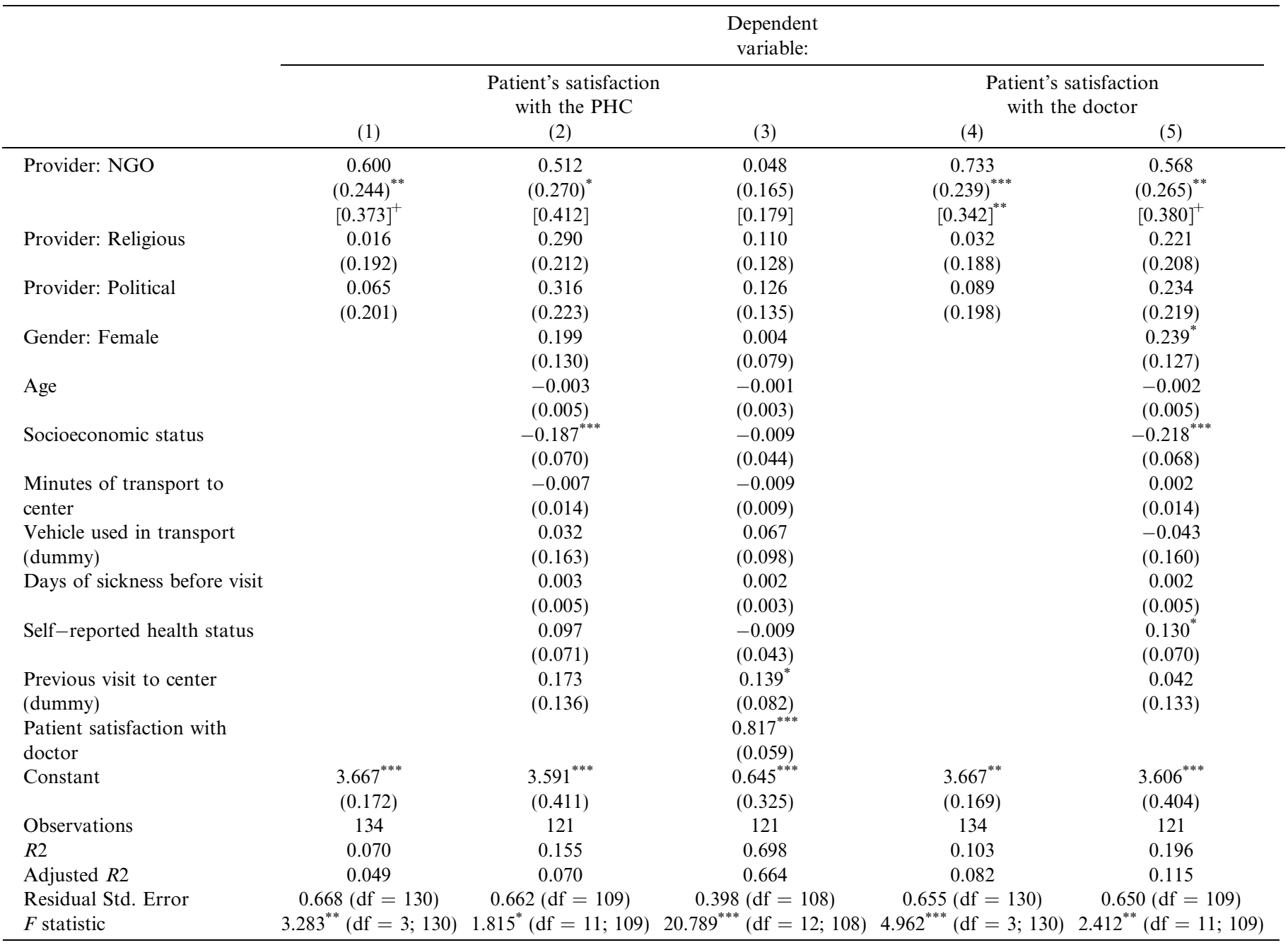

Note: Normal standard errors are in parentheses, and block-bootstrapped standard errors $(10,000$ resampling $)$ are in brackets. ${ }^{*} p<0.1 ;{ }^{* *} p<0.05$; ${ }^{* * *} p<0.01 ;{ }^{+} p<0.15$.

\section{STATISTICAL ANALYSES OF SUBJECTIVE HEALTH CARE QUALITY}

\section{(a) Controlling for potential confounders}

The descriptive analysis suggests that patient satisfaction levels are higher at health facilities run by secular NGOs. A linear regression model that uses dummies for each provider type with public institutions as the benchmark category shows that this association is also statistically significant at the $5 \%$ level (Table 3 Column 1). Column 2 adds to the model a number of patient characteristics that could affect both the choice of provider and patient satisfaction. These potential confounders include personal characteristics, general health conditions, and distance traveled to the facility. ${ }^{14}$ The coefficient on the type NGO variable remains positive and statistically significant. In Column 3 , we then show that patient satisfaction with the facility is almost perfectly predicted by patient satisfaction with the doctor.

Taking satisfaction with the doctor as the dependent variable, Columns 4 and 5 suggest that patients are more satisfied with doctors in facilities run by secular NGOs, even after controlling for the same battery of potential confounders. The relationship is statistically significant at the conventional 5\% level. For our key variable of interest - the variable indicating NGO type-we also report block-bootstrapped standard errors to overcome the potential problem of clustering at the level of the health center. ${ }^{15}$ Even though the larger standard errors show that the uncertainty around the estimated effect of NGO type increases with block-bootstrapping, the effects are still arguably robust, especially given the small sample size.

The estimations in Table 3 suggest that patient satisfaction with doctors in NGO-run facilities is almost one standard deviation higher than that of patients in public institutions. In other words, the relationship is substantively important, calling for further exploration. ${ }^{16}$ Because patient satisfaction with the doctor almost perfectly predicts satisfaction with the facility, we focus on satisfaction with doctors as the dependent variable in the remainder of the analyses.

\section{(b) Potential mediators}

What factors might mediate between provider type, i.e., the apparent NGO advantage, and patient satisfaction? We focus on doctor-level variables as potential mediators, since patient satisfaction is determined by satisfaction with the doctor to a 
Table 4. Regressing potential mediators on provider type

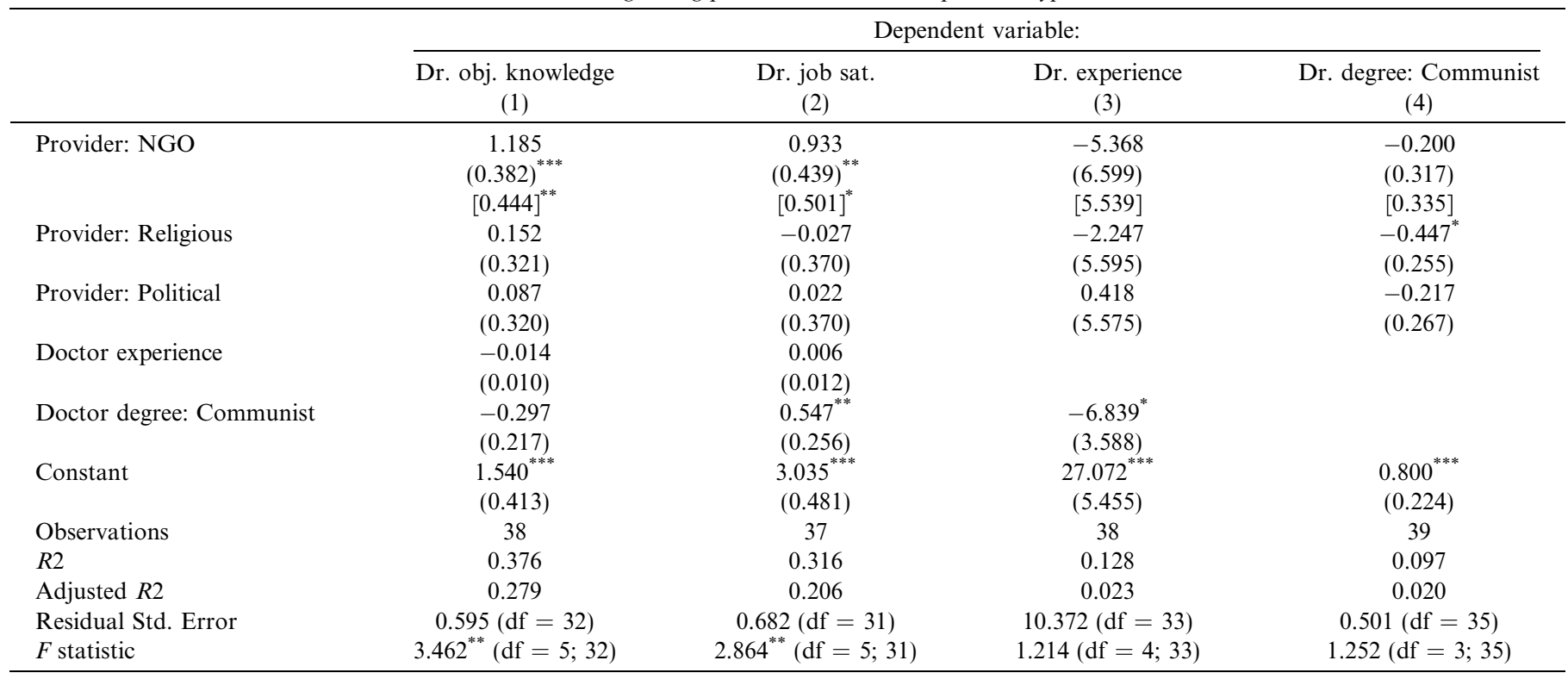

Note: Normal standard errors are in parentheses, and block-bootstrapped standard errors $(10,000$ resamplings $)$ are in brackets. ${ }^{*} p<0.1 ;{ }^{* *} p<0.05$; ${ }^{* *} p<0.01 ;{ }^{+} p<0.15$.

very high degree. Potential mediators at the level of the doctor, which might both be affected by provider type and affect patient satisfaction, include: ${ }^{17}$

- Medical knowledge: Patients may be more satisfied with doctors who are more competent, as measured by their medical knowledge.

- Job satisfaction: The vignettes survey asks doctors how satisfied they are with organization where they work. If doctors in NGO-run facilities express greater satisfaction with the organization running the center, they may be more responsive to the needs of the patients and may exhibit higher levels of professionalism, which would then lead patients to rate the doctors more favorably.

- Professional experience: Patients may be more satisfied with doctors with more (or less) experience, and levels of experience might also be correlated with provider type.

- Perceived doctor credentials: Some Lebanese regard doctors who received their medical degrees from former communist countries as less qualified, and therefore patients may be less satisfied with doctors with these credentials, irrespective of their capabilities.

To see if any of the above factors act as potential mediators, we first need to demonstrate that there is a statistically significant relationship between a given variable and provider type, especially NGO type. To that end, we regress these variables on provider types along with appropriate controls (see Table 4). The results suggest that there is a positive and significant relationship between NGO type and doctor medical knowledge and with doctor job satisfaction. In other words, doctors who work in NGOs are both more competent in what they do and more satisfied with their current job. Thus, these two factors may mediate the positive association between secular NGOs as the provider type and patient satisfaction.

\section{(c) Estimating the mediation effect}

We now test the link between the potential mediators and the dependent variable, i.e., patient satisfaction. To test both of the hypothesized relationships (between the explanatory variable and the potential mediator, and between the potential mediator and the dependent variable) simultaneously, we use the mediation analysis technique and the mediation package (Imai, Keele, \& Tingley, 2010; Imai, Keele, Tingley, \& Yamamoto, 2011; Imai \& Yamamoto, 2013). Unlike other causal mediation analysis techniques, this method enables non-parametric identification of the mediation effect, even if linear relationships are assumed between the explanatory variable and the mediator and between the explanatory variable and the dependent variable. It produces estimations of the average causal mediation effect (ACME), which represents the portion of the estimated effect of the explanatory variable on the outcome variable that goes through the tested mediator.

To estimate the ACME for each potential mediator, the mediation package requires specification of an outcome model and a mediator model, through which it then generates predictions for the mediator and the outcome and nonparametrically computes the ACME. We specify the same outcome model as in Column 5 of Table 3, while adding the potential mediators and controls at the doctor level, as required by this technique. Potential mediator variables are at the level of doctor, thus the outcome model turns into a multi-level model. For the potential mediators-doctor medical knowledge and doctor job satisfaction-the model is specified as in Column 1 and Column 2 of Table 4, respectively. Thus, the model specifications for the mediator and the outcome can be depicted as follows:

$$
\begin{aligned}
& M_{j}=\alpha+\beta T_{j}+\delta V_{j}+\varepsilon_{j} \\
& Y_{i j}=\lambda_{j}+\varsigma X_{i j}+v_{i j} \\
& \lambda_{j}=\lambda+\theta T_{j}+\phi M_{j}+\kappa V_{j}+\omega_{j}
\end{aligned}
$$

in which $V_{j}$ is the vector for doctor-level covariates, $X_{i j}$ is the vector for patient-level covariates, and $\varepsilon_{j}, v_{i j}$ and $\omega_{j}$ are each normally distributed stochastic errors with zero mean. The ACMEs are identified with $90 \%$ quasi-Bayesian confidence 
Table 5. Estimating the Average Causal Mediation Effect (ACME)

\begin{tabular}{lcccc}
\hline Potential mediator variable & $\begin{array}{c}\text { Average causal } \\
\text { mediation effect }\end{array}$ & $\begin{array}{c}90 \% \text { CI lower } \\
\text { limit }\end{array}$ & $\begin{array}{c}90 \% \text { CI upper } \\
\text { limit }\end{array}$ & $\begin{array}{c}\text { Proportion of the } \\
\text { total effect through } \\
\text { this mediator }(\%)\end{array}$ \\
\hline Doctor medical knowledge & 0.135 & -0.213 & 0.536 & 17.65 \\
Doctor job satisfaction & 0.244 & {$[-0.261]$} & {$[0.617]$} & 0.621 \\
& & {$[-0.007$} & 28.17 \\
\hline
\end{tabular}

Note: The "mediate" command in the mediation package in $\mathrm{R}$ is used to calculate the estimations reported in this table. ACME estimate and quasiBayesian confidence intervals for each potential mediator are calculated with 1000 simulations. Block-bootstrapped confidence interval limits (individual centers are used as blocks) are in brackets. When block-bootstrapping, 100 simulations were used for each of the 500 resamplings.

intervals based on 1,000 simulations. The results are presented in Table 5.18

Table 5 suggests that doctor job satisfaction is a much more likely mediator between provider type (NGO, specifically) and patient satisfaction than doctor medical knowledge. Even though doctors in NGOs usually have higher levels of medical knowledge, patients treated by these doctors are not necessarily more satisfied with the care they receive, a logical finding given that non-medical professionals are not often qualified to evaluate technical training. This is represented in the first line of Table 5, in which the ACME of medical knowledge is estimated to be not statistically different from zero.

The second line of Table 5 suggests that the positive effect of NGOs on patient satisfaction might at least partially be due to the higher job satisfaction of doctors working in facilities run by secular organizations. The ACME for doctor job satisfaction is estimated to be more than 0.2 , and the values within the $90 \%$ confidence interval are also different from zero. The greater job satisfaction of doctors in secular NGOs explains on average $28 \%$ of the NGO advantage in garnering higher levels of patient satisfaction.

As in the previous models, we employ the blockbootstrapping technique in the mediation analysis to overcome potential correlation in error terms due to the unmeasured effects of individual health centers. Even with wider confidence intervals, doctor job satisfaction remains a much more likely mediator between provider type and patient satisfaction. 19

\section{(d) Checking the sensitivity to the assumptions of causal mediation}

The mediation analysis technique we used in this paper inherently argues causality and, to that end, makes an important assumption called "sequential ignorability." In addition to the regular "ignorability of the treatment" assumption, sequential ignorability assumes no pretreatment and posttreatment confounding between the mediator and the outcome variable. In other words, no variable before or after the treatment should cause both the mediator (1n our case, doctor job satisfaction) and the outcome (in our case, patient satisfaction with the doctor). In this section, we provide some baseline checks on whether this assumption holds.

To test for pretreatment confounding between the mediator and the outcome, Imai et al. (2010) offer a sensitivity analysis in which the sensitivity of the ACME estimations can be tested. This analysis is based on the correlation, denoted with $\rho$, between the error term of the model predicting the mediator and the error term of the model predicting the outcome. If sequential ignorability holds, all relevant pretreatment confounders have been conditioned on, and thus $\rho$ equals zero. Through simulation, it is possible to calculate the values of $\rho$ for which the ACME is zero or its confidence interval is zero. If the estimates of the ACME contain zero at lower values of $\rho$, this indicates a higher possibility that there might be unmeasured pretreatment confounders that cause both the mediator and the outcome, and therefore the suggested causal path might be spurious.

Figure 1 reports the sensitivity analysis, i.e., ACME estimate for doctor's job satisfaction as a function of $\rho$, for the causal path being argued in this paper. ${ }^{20}$ Accordingly, ACME turns to zero when $\rho$ is 0.2 . In other words, if there is a pretreatment confounder that leads to a 0.2 correlation between the error terms, the ACME estimate turns to 0. Moreover, the lower bound of the confidence interval for ACME turns zero in very small amounts of correlation. This suggests a moderate degree of robustness of the ACME estimate to pretreatment confounders. Yet, the formulation of the question for doctor's job satisfaction ${ }^{21}$ gives some level of confidence for the unconfounded and post-treatment characteristic of this variable. Furthermore, a larger sample size would likely establish the robustness of these findings.

Sequential ignorability also assumes that there is no posttreatment confounding between the mediator and outcome variables. The most important reason for posttreatment confounding might be a causal relationship between potential mediators. Following Imai and Yamamoto (2013), we regress the mediator of interest (in this case, doctor job satisfaction)

\section{Sensitivity with Respect to Error Correlation}

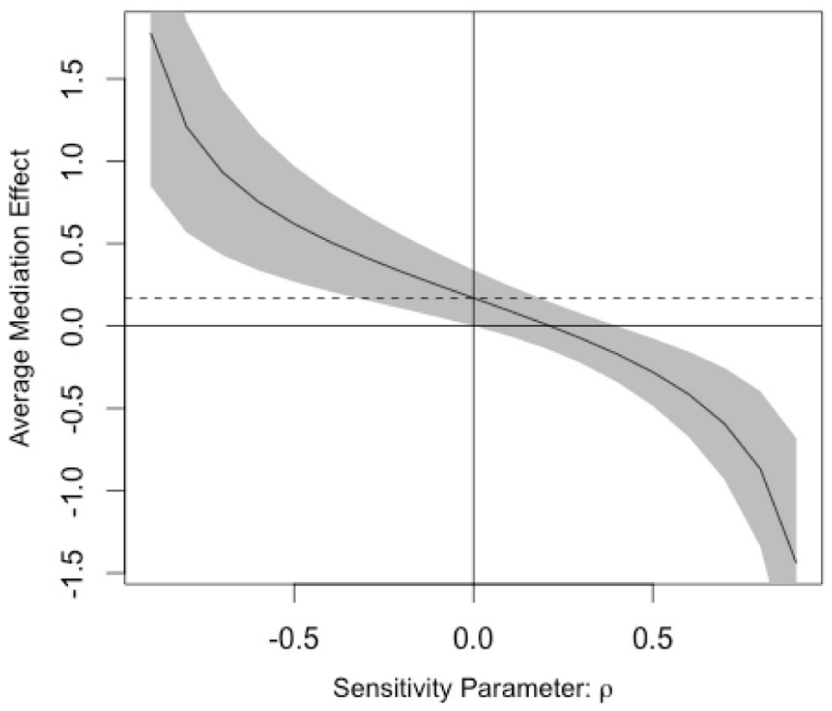

Figure 1. Sensitivity analysis for doctor's job satisfaction as mediator 
on the other potential mediator (doctor medical knowledge) using the treatment and appropriate control variables. Both the regression and an F-test suggest that there is no significant relationship between the two potential mediating factors (See Online Appendix Part A6). It is important to recall that this is a baseline check: Even though we fail to reject the null hypothesis of no conditional association, we cannot fully rule out the possibility of a causal relationship between potential mediators. Nevertheless, this result gives us more confidence that at least some of the positive effect of NGO provider type on patient satisfaction is mediated through doctor satisfaction with their position in the health center.

\section{EXPLAINING THE SECULAR WELFARE ADVANTAGE?}

Analyses of diverse indicators of the quality of primary health care in Lebanon suggest that doctors at facilities run by secular NGOs are more satisfied with and committed to the health centers where they work and that patients have more favorable views of providers at these facilities. Conversely, patients express more negative perceptions of providers at facilities run by religious charities and, in some respects, by political groups than those run by other types of institutions, while measures of infrastructure and governance procedures show no meaningful variation across institutional type. Furthermore, doctors at secular NGOs appear to be more competent at their profession.

These findings contradict some theoretical and empirical expectations. First, several strands of literature suggest that religious charities deliver superior services, whether because their charitable missions serve to motivate staff members or because exigent religious organizational characteristics attract especially committed personnel. Second, the results may be surprising in the context of the Lebanese welfare regime, where public and secular providers are widely perceived as either inferior or more under-resourced than religious and political groups while FBOs of various stripes and sectarian parties dominate the political system and control substantial public and private resources.

What might account for the ostensible secular advantage in service delivery in Lebanon? Paradoxically, the relative marginalization of secular organizations in politics and the welfare regime may work in their favor. On the supply side, given that they lack influence in the sectarian system, secular providers may attract doctors who are especially committed to a sense of professionalism and have little to gain beyond the satisfaction of advancing non-sectarian, humanitarian principles, a core mission of the secular NGOs in the sample. ${ }^{22}$ These ideological commitments may serve as sources of "intrinsic motivation" (Ryan \& Deci, 2000) for staff members. Furthermore, secular groups in Lebanon do not have well-developed patronage and clientelist networks (Cammett, 2014) and, therefore, their professional staff cannot fulfill reciprocal obligations through service in these facilities nor can they derive material benefits beyond gaining professional experience and building their professional reputations, a motivation shared by doctors working in all types of health networks. As a result, on average doctors who work at secular NGOs may be more likely to select into these organizations in order to fulfill professional goals. ${ }^{23}$

Our findings about a secular welfare advantage are particularly strong with respect to subjective measures of quality. On the demand side, beneficiaries may perceive secular NGOs to be less corrupt since these groups are effectively shut out of national politics and derive no benefit from the sectarian power-sharing system, which is widely disparaged by Lebanese (Atallah, 2012). As a result, secular NGOs, which are not tainted by association with the corrupt and ineffective political system, may benefit from the same kind of reputational advantage that some religious actors enjoy in polities with corrupt secular rulers (Brooke, 2014; Cammett \& Luong, 2014; Masoud, 2014; Pepinsky, Liddle, \& Mujani, 2012). Furthermore, low expectations of secular NGOs could lead to inflated satisfaction ratings when patients discover that the services rendered are better than anticipated given the relatively low level of resources that they command in comparison with other provider types. The role of prior expectations in shaping subjective quality should be tested more systematically with public opinion data in future research within and beyond Lebanon.

In short, in Lebanon, where secular groups are excluded from patronage networks and operate on the fringes of power, serving in affiliated organizations calls upon personnel to make personal sacrifices by foregoing opportunities to benefit from established patronage networks and by devoting themselves to groups that are marginalized in political and social life. In turn, the high commitment of staff members to the programs and activities of secular groups, including in the realm of welfare, may result in more favorable perceptions of their services. Our tentative explanation therefore points to the ways in which sociopolitical context mediates the real and perceived activities of service providers with distinct organizational missions.

\section{CONCLUSION}

Based on findings from Lebanon, which features diverse public and non-state service providers, this paper explores whether different types of organizations exhibit a welfare advantage in the delivery of basic health care. Insights from the literatures on FBOs and the economics of religion as well as specific characteristics of the Lebanese welfare regime suggest that religious charities and, especially, sectarian parties should offer higher quality services than other types of providers, notably the public sector and secular NGOs. We find instead that secular NGOs exhibit an apparent welfare advantage on some objective measures (i.e., doctor knowledge) and, more strongly, on subjective measures. To explain the apparent secular welfare advantage, we hypothesize that secular groups enjoy a reputational advantage in Lebanon, where religion is associated with the corrupt sectarian power-sharing system. Secular NGOs, which offer few material rewards to their staff, may also attract qualified and committed personnel. In short, sociopolitical context may mediate popular perceptions of distinct welfare institutions and may even shape selection effects so that more qualified professionals opt to work for some types of organizations over others.

These insights from Lebanon are most clearly generalizable to other polities with politically salient identity-based cleavages and where diverse non-state providers play important roles in the welfare mix. Yet the Lebanese may case offer relevant insights into the politics of service delivery in other places, too, especially in light of the growing importance of non-state provision, including in countries with more statist economic legacies. Furthermore, the findings call for a broader investigation of the interplay between political context, organizational mission and the quality of social service provision. In particular, future 
research should explore the ways in which formal and informal features of the political system shape the types of provider organizations that attract the most competent personnel, which affects service quality in tangible ways, and citizen perceptions of the relative proficiency of distinct providers, which can affect subjective evaluations of providers as well as patient compliance with medical advice, among other outcomes.

\section{NOTES}

1. While we recognize that the term "secular" is contested and has multiple meanings (Asad, 2003), here we use the term to refer to organizations that are not connected to any religious group or community and are not linked to political parties, religious or otherwise. In the Lebanese context, secular organizations often explicitly distinguish themselves from religious and sectarian groups and ideologies.

2. We distinguish between religious and sectarian groups. While both are linked to religious denominations or communities, only the latter have explicitly political goals. Examples of religious organizations include the Maronite Church, the Sunni Dar al-Fatwa or Shi'a Islamic Higher Council. The Christian Kataeb and Lebanese Forces, predominantly Sunni Future Movement, and the Shi'a Hezbollah and Amal Movement are examples of sectarian parties. Note that we sometimes refer to sectarian groups as "political" in the discussion and in the analyses.

3. Reinikka and Svensson (2010) provide evidence of a faith-based welfare advantage in their study of religious non-profit organizations in Uganda. As the authors $(2010,1161)$ note, "These findings are consistent with the view that religious nonprofit providers are intrinsically motivated to serve (poor) people-working for God seems to matter!".

\section{A classic example is the Church of Jesus Christ of Latter-Day Saints.}

5. For reviews, see Lieberman, 2015 and McLoughlin \& Batley, 2012.

\section{These data are from 2008 .}

7. Several of the instruments were adapted from the work of Jishnu Das and his collaborators (Das, 2011; Das et al., 2008).

8. Unfortunately, most interviewees declined to provide information on the finances and budgets of their respective centers in the survey, however, follow-up interviews with the heads of health networks successfully gathered data on staff compensation rates for many centers in the sample.

9. Hawthorne effects refer to the tendency of interviewees or the subjects of a study to improve their behavior or productivity when they are conscious of being observed.

10. Because sect is so politicized in Lebanon, the names of the hypothetical patients were deliberately chosen to be neutral with respect to religious identity. For example, names that tend to be used in the Shi'a community, such as Hussein, or in the Christian community, such as Tony, were purposefully avoided.

11. The items for the "Workplace equipment" include, for instance, hand-washing facilities with soap and running water, a generator for use during regular power cuts and to protect refrigeration for vaccines and medications, and a locked filing cabinet for patient records. The items for the "Health equipment" include, for instance, stethoscopes, electric sterilizers, disposable syringes, and EKG machines. Please see the Supplemental Online Appendix Part A1 for the full list of items included in the construction of these two indicators.

12. In the 2013 Arab Barometer survey in Lebanon, over $69 \%$ of respondents reported that they "absolutely do not trust" government while only $27 \%$ expressed similar sentiments about civil society organizations.

13. The specific physical examinations in this study include the use of a stethoscope, blood pressure measurement, gauging body temperature, palpitation, checking the pulse, and other physical examinations recorded by the observer.

14. For more information on and descriptive statistics of these control variables, we refer the reader to the Supplemental Online Appendix Part A2

15. Block-bootstrapping is a technique of estimating uncertainty when there is a legitimate concern about correlated error terms in a model (or within-group dependence), but the number of clusters is small for calculating cluster-robust standard errors (Cameron, Gelbach, \& Miller, 2011). In our case, we use block-bootstrapping as our data are clustered at the level of the health center.

16. Hierarchical linear models with varying intercepts at the doctor level or the PHC level, and an ordered probit model generate very similar results in terms of substantial and statistical significance to the results of the linear regression model we report in the main body of text. See Online Appendix Part A3 for alternative specifications of the outcome model. Moreover, in Online Appendix Part A4 we also provide the results of several outcome model specifications with the addition of patient load variables at the PHC level. Lastly, to show that our results are not modeldependent, we provide the results of matching in Online Appendix Part A5. Matching leads to very similar results.

17. See the Online Appendix Part A2 for descriptive statistics on the doctor-level potential mediator variables.

18. To estimate the mediation effect, both in the model predicting the outcome and in the model predicting the mediator we use smaller versions of the patient-level and doctor-level datasets, because "the current version of the mediation package requires that the model frames of the mediator and outcome models contain the exact same set of groups, which becomes important when each model contains different covariates and some groups drop out of the model frames due to missingness." (See Tingley, Yamamoto, Hirose, Keele, \& Imai, 2014.) Thus, the smaller version of the patient-level dataset does not include the patients who were examined by doctor eliminated from the mediator model due to data missingness. The estimations of the outcome model based on the larger dataset $(n=135)$ and the smaller dataset $(n=97)$ are qualitatively the same.

19. The marked increase in the confidence interval indicates that some centers run by secular NGOs garner higher levels of patient satisfaction through higher levels of doctor job satisfaction than others. This deserves further exploration in future extensions of the study.

20. The current version of the mediation package does not allow for sensitivity analyses when multilevel models are used to predict the outcome and the mediator. Therefore, for the sake of the sensitivity analysis, we used a linear regression in the outcome model. The critical quantity of interest, i.e., the level of sensitivity parameter $\rho$, at which the ACME estimate turns to zero, would not differ between models using multilevel regression and models using linear regression. 
21. "How would you rate your satisfaction with your job in this health center?" (emphasis added).

22. Interview by Melani Cammett with Chief Medical Officer, Lebanese NGO, Beirut, January 19, 2015; Interview by Melani Cammett with Director, Lebanese NGO, Beirut, January 15, 2015.
23. It is possible that some qualified personnel may not work in religious or political institutions because they lack the necessary connections. We are skeptical of this interpretation, however, because many have the option to conform with the religious or political objectives and rules of such groups, and thereby become more integrated in corresponding networks, but choose not to do so.

\section{REFERENCES}

Asad, T. (2003). Formations of the secular: Christianity, Islam, modernity. Palo Alto, CA: Stanford University Press.

Atallah, S. (2012). Arab Barometer II: Lebanon Country Report. Ann Arbor, MI: Arab Barometer.

Basu, S., Andrews, J., Kishore, S., Panjabi, R., \& Stuckler, D. (2012). Comparative performance of private and public healthcare systems in low-and middle-income countries: A systematic review. PLoS Medicine, 9(6), e1001244.

Berendes, S., Heywood, P., Oliver, S., \& Garner, P. (2011). Quality of private and public ambulatory health care in low and middle income countries: Systematic review of comparative studies. PLoS Medicine, 8 (4), e1000433.

Brass, J. (2016). Allies or adversaries: NGOs and the state in Africa. New York, NY: Cambridge University Press.

Brinkerhoff, D. W. (1999). Exploring state-civil society collaboration: policy partnerships in developing countries. Nonprofit and Voluntary Sector Quarterly, 28(1 suppl), 59-86.

Brooke, S. (2014). Why do Islamists provide social services? In Rethinking Islamist politics. Washington, DC: Program on Middle East Political Science.

Cameron, A. C., Gelbach, J. B., \& Miller, D. L. (2011). Robust inference with multiway clustering. Journal of Business \& Economic Statistics, 29 (2), 238-249.

Cammett, M. (2014). Compassionate communalism: Welfare and sectarianism in Lebanon. Ithaca, NY: Cornell University.

Cammett, M., \& Luong, P. J. (2014). Is there an Islamist political advantage?. Annual Review of Political Science, 17, 187-206.

Cammett, M., Lynch, J., \& Bilev, G. (2015). The influence of private health care financing on citizen trust in government. Perspectives on Politics, 13(04), 938-957.

Cammett, M., \& MacLean, L. M. (Eds.) (2014). The politics of non-state welfare. Ithaca, NY: Cornell University Press.

Christensen, T., \& Lægreid, P. (2005). Trust in government: The relative importance of service satisfaction, political factors, and demography. Public Performance \& Management Review, 28(4), 487-511.

Clarke, G., Jennings, M., \& Shaw, T. (Eds.) (2007). Development, civil society and faith-based organizations: Bridging the sacred and the secular. Springer.

Cnaan, R., \& Boddie, S. C. (2002). The invisible caring hand: American congregations and the provision of welfare. New York, NY: NYU Press.

Das, J. (2011). The quality of medical care in low-income countries: From providers to markets. PLoS Medicine, 8(4), e1000432.

Das, J., \& Hammer, J. (2007). Money for nothing: The dire straits of medical practice in Delhi, India. Journal of Development Economics, 83 (1), 1-36.

Das, J., \& Hammer, J. (2014). Quality of primary care in low-income countries: Facts and economics. Annual Review of Financial Economics, 6(1), 525-553.

Das, J., Hammer, J., \& Leonard, K. (2008). The quality of medical advice in low-income countries. The Journal of Economic Perspectives, 22(2), 93-114.

DeHaven, M. J., Hunter, I. B., Wilder, L., Walton, J. W., \& Berry, J. (2004). Health programs in faith-based organizations: Are they effective?. American Journal of Public Health, 94(6), 1030-1036.

Donabedian, A. (1988). The quality of care: How can it be assessed? JAMA, 260(12), 1743-1748.

Evers, A. (2005). Mixed welfare systems and hybrid organizations: Changes in the governance and provision of social services. International Journal of Public Administration, 28(9-10), 737-748.

Iannaccone, L. R. (1994). Why strict churches are strong. American Journal of Sociology, 99(5), 1180-1211.

Imai, K., Keele, L., \& Tingley, D. (2010). A general approach to causal mediation analysis. Psychological Methods, 15(4), 309.
Imai, K., Keele, L., Tingley, D., \& Yamamoto, T. (2011). Unpacking the black box of causality: Learning about causal mechanisms from experimental and observational studies. American Political Science Review, 765-789.

Imai, K., \& Yamamoto, T. (2013). Identification and sensitivity analysis for multiple causal mechanisms: Revisiting evidence from framing experiments. Political Analysis, 141-171.

Karam, A., Clague, J., Marshall, K., \& Olivier, J. (2015). The view from above: Faith and health. The Lancet, 386(10005), e22-e24.

Klassen, A., Miller, A., Anderson, N., Shen, J., Schiariti, V., \& O'donnell, M. (2010). Performance measurement and improvement frameworks in health, education and social services systems: A systematic review. International Journal for Quality in Health Care, 22(1), 44-69.

Leonard, K., \& Masatu, M. C. (2006). Outpatient process quality evaluation and the Hawthorne Effect. Social Science and Medicine, 63(9), 2330-2340.

Lieberman, E. S. (2015). The comparative politics of service delivery in developing countries. In The Oxford handbook of politics of development. New York, NY: Oxford University Press.

Masoud, T. (2014). Counting Islam: Religion, class, and elections in Egypt. New York, NY: Cambridge University Press.

McLoughlin, C., \& Batley, R. J. (2012). The politics of what works in service delivery: An evidence-based review. Working Paper 06, Effective States and Inclusive Development Research Centre (ESID), School of Environment and Development Department, University of Manchester.

Pepinsky, T. B., Liddle, R. W., \& Mujani, S. (2012). Testing Islam's political advantage: Evidence from Indonesia. American Journal of Political Science, 56(3), 584-600.

Pestoff, V., \& Brandsen, T. (2013). Co-production: The third sector and the delivery of public services. New York, NY: Routledge.

Reinikka, R., \& Svensson, J. (2010). Working for god? Evidence from a change in financing of nonprofit health care providers in Uganda. Journal of the European Economic Association, 8(6), 1159-1178.

Rockers, P. C., Kruk, M. E., \& Laugesen, M. J. (2012). Perceptions of the health system and public trust in government in low-and middleincome countries: Evidence from the World Health Surveys. Journal of Health Politics, Policy and Law, 37, 405-437.

Ryan, R. M., \& Deci, E. L. (2000). Intrinsic and extrinsic motivations: Classic definitions and new directions. Contemporary Educational Psychology, 25(1), 54-67.

Salti, N., \& Chaaban, J. (2010). The role of sectarianism in the allocation of public expenditure in postwar Lebanon. International Journal of Middle East Studies, 42(04), 637-655.

Stelfox, H. T., \& Straus, S. E. (2013). Measuring quality of care: Considering measurement frameworks and needs assessment to guide quality indicator development. Journal of Clinical Epidemiology, 66(12) $1320-1327$

Summerskill, W., \& Horton, R. (2015). Faith-based delivery of sciencebased care. The Lancet, 386(10005), 1709-1710.

Thachil, T. (2014). Elite parties, poor voters: How Social services win votes in India. New York, NY: Cambridge University Press.

Tingley, D., Yamamoto, T., Hirose, K., Keele, L., \& Imai, K. (2014). Mediation: $\mathrm{R}$ package for causal mediation analysis. Journal of Statistical Software, 59, 1-38.

Tuan, T., Dung, V. T. M., Neu, I., \& Dibley, M. J. (2005). Comparative quality of private and public health services in rural Vietnam. Health Policy and Planning, 20, 319-327.

Unruh, H. R., \& Sider, R. J. (2005). Saving souls, serving society: Understanding the faith factor in church-based social ministry. New York, NY: Oxford University Press.

Wilkinson, R. G., \& Marmot, M. (2003). Social determinants of health: The solid facts. World Health Organization. 
Wood, G., \& Gough, I. (2006). A comparative welfare regime approach to global social policy. World Development, 34(10), 1696-1712.

World Bank (2004). Making services work for poor people. Washington, DC: World Bank.

World Bank (2016). Making politics work for development: Harnessing transparency and citizen engagement. Washington, DC: World Bank.

Wuthnow, R. (2004). Saving America? Faith-based services and the future of civil society. Princeton, NJ: Princeton University Press.
APPENDIX A. SUPPLEMENTARY DATA

Supplementary data associated with this article can be found, in the online version, at http://dx.doi.org/10.1016/ j.worlddev.2017.04.013.

Available online at www.sciencedirect.com

\section{ScienceDirect}

